\title{
LA COMPETENCIA DE LA RAZÓN PRÁCTICA EN LA CONFORMACIÓN DEL HUMANISMO GINERIANO ${ }^{1}$
}

\author{
Delia MANZANERO \\ Universidad Rey Juan Carlos de Madrid
}

\section{Resumen}

En este artículo, sustentamos que el conocimiento de las construcciones teóricas del siglo XVI puede resultar muy útil con vistas a la conformación de la filosofía jurídica gineriana y los esquemas de organización social de los siglos XIX y XX. Ciertamente no se trata de trasladar sin más con una conciencia anacrónica, como en alguna ocasión se ha pretendido, aquellos esquemas al presente, pues el solo establecimiento de algunas analogías no es suficiente para difuminar una distancia de tres siglos. En cualquier caso, creemos que un estudio detenido de estos esfuerzos históricos por revitalizar principios jurídicos y sociales como el de razón práctica, puede ser de gran utilidad para comprender el contexto en que se fraguó la filosofía jurídica de Francisco Giner y su amplificación y extensión durante la Edad de Plata española. Al mismo tiempo, creemos que su estudio posee el relevante interés de entrañar una posible lectura de los clásicos iusnaturalistas hispanos desde y para la cultura filosófico-jurídica contemporánea, por lo que también dedicaremos algunas líneas a este tema.

Palabras clave: Francisco Giner de los Ríos; razón práctica; iusnaturalismo; derecho.

\begin{abstract}
In this article, I support the fact that knowing the theoretical constructs of the sixteenth century can be very useful for shaping Giner's legal philosophy and the social organisation systems of the nineteenth and twentieth centuries. This is certainly

1. Esta investigación se realiza en el marco del proyecto de investigación «Fundamentos y desarrollo de la idea krausista de Europa: universalismo, internacionalismo, educación y cultura» (I+D+i: FFI2011-23682, 2012-2015) de la Universidad Pontificia Comillas, dirigido por Ricardo Pinilla Burgos y financiado por el Ministerio de Economía y Competitividad. Asimismo, esta investigación se inscribe dentro de una Ayuda Juan de la Cierva - Formación Posdoctoral adscrita a la Universidad Rey Juan Carlos de Madrid y financiada por el Ministerio de Economía y Competitividad (FPDI-2013-17242).
\end{abstract}

Anales, 27 (2015), pp. 139-157

DOI: 10.14198/ALEUA.2015.27.08 
not a question of simply transferring those systems to the present time with an anachronistic consciousness, as it has on some occasion been intended, for the mere establishment of some analogies is not enough to blur a distance of three centuries. In any case, I believe that a careful study of these historical efforts to revitalise legal and social principles such as that of practical reason, may be very useful to understand the context where the legal philosophy of Francisco Giner was forged, as well as its amplification and extension during the Spanish Silver Age. At the same time, I believe that studying this question has the relevant interest of involving a possible reading of Iusnaturalist Hispanic Classics from and for contemporary philosophical and legal culture, so I will also dedicate some lines to this subject.

Keywords: Francisco Giner de los Ríos; practical reason; Iusnaturalism; law.

Cuando se trata de analizar las múltiples influencias que ha recibido la obra jurídica y sociológica de Francisco Giner de los Ríos, es preciso reparar en ese proceso de recuperación krausista de los temas y la metodología jurídica de los clásicos hispanos de la Escuela del Derecho Natural. Para tratar de esta etapa de recuperación de las tesis iusnaturalistas que se despliega durante el siglo XIX y primeras décadas del XX, subrayaremos las concomitancias existentes entre los krausistas españoles y los clásicos españoles, para llegar hasta lo que consideramos un eslabón imprescindible en esta fase de recuperación de la doctrina del Derecho Natural: la lectura que hace el iusnaturalismo krausista de los clásicos hispanos.

Antes de iniciar este recorrido, consideramos oportuno señalar brevemente lo que nos motivó a emprender esta investigación sobre los precedentes de la filosofía social y jurídica de Giner en la Escuela de Derecho Natural española. El principal estímulo fue, sobre todo, el hallazgo de las patentes y enriquecedoras relaciones que pueden establecerse entre sus doctrinas, aunque quizá, el leitmotiv determinante para abordar este estudio fue la lectura de un artículo de Adolfo Posada, "El Cuerpo místico" del P. Suárez y el "Organismo social” del Maestro Giner», cuyo título es ya indicativo de ese intento de establecer de modo expreso la estrecha relación existente entre ambas corrientes de pensamiento:

Pienso que un estudio imparcial y sereno de la obra de no pocos de los «grandes españoles» de los siglos XVI y XVII — teólogos y filósofos del derecho, metafísicos y místicos- descubriría relaciones profundamente sugestivas entre sus actitudes espirituales, sus concepciones generales del mundo ético y jurídico y las de los llamados, entre nosotros, «krausistas», que no obstante sus atavíos europeos y a pesar de su formación ideológica bajo el influjo de las corrientes centrales de la filosofía alemana —Kant, 
Fichte, Schelling, Hegel, pero, sobre todo, Krause- tenían la raíz más honda de su alma en lo más íntimo del pensamiento místico y metafísico español. Algo de esto apuntaba D. Juan Valera en estas líneas de un pueblo a una de las ediciones de Pepita Jiménez (escrito en 1886, en Nueva York, 5. a edición de La Lectura, de 1927). «Entonces, decía Valera, me empeñé en demostrar que si Sanz del Río y los de su escuela eran panteístas, nuestros místicos de los siglos XVI y XVII lo eran también; y que si los unos tenían por predecesores a Fichte, Schelling, Hegel y Krause, Santa Teresa, San Juan de la Cruz y el iluminado y extático Padre Miguel de la Fuente, por ejemplo, seguían a Tauler y a otros alemanes, sin que yo negase a ninguno la originalidad española, sino reconociendo en esta encadenada transmisión de doctrina el progresivo enlace de la civilización europea». No lo olvidemos: «los de la escuela» de Sanz del Río, lo recuerda Valera, eran Salmerón, Giner, Azcárate, Federico de Castro y González Serrano (Posada, 1928: 118).

Bien claro parece de este texto de Posada, extractado del Boletín de la Institución Libre de Enseñanza, que el krausismo español no es hijo de la filosofía idealista alemana con exclusividad, y conviene reparar, pues, en que, junto a esos atavíos europeos, le acompañaron otros adornos y prendas que provendrían de la propia historia del pensamiento español. Por esta razón, trataremos de dar cuenta de este fenómeno de recuperación del legado de nuestros clásicos, que fue llevado a cabo, paradójicamente, no por quienes se presentaban como tradicionalistas, sino desde las premisas reformadoras y liberales krausistas que auspiciaron una lectura renovadora, en clave liberal y democrática, de sus doctrinas.

Con respecto a este tema, dice Adolfo Posada que este interés suyo por recuperar para su época la tradición de pensamiento de la Escuela de Derecho Natural española se despertó «al leer, de nuevo, en el gran infolio del P. Francisco Suárez S. J., en el tratado De Legibus ac Deo Legislatore, edición de 1613, puesto ahora en castellano por Torrubiano y Ripio, 1918, y al comparar o relacionar algunos de los razonamientos y concepciones de aquel insigne pensador español, teólogo y filósofo de primera magnitud, uno de los magni hispani que estudia Kohler, con ciertas ideas capitales del maestro Francisco Giner, expuestas y explicadas estas en algunos de sus libros, verbigracia, en sus estudios de Filosofía y Sociología y en varios de sus trabajos sobre La persona social» (Posada, 1928: 118). Corresponde, pues, a Adolfo Posada el incuestionable mérito de haber impulsado este proceso reivindicativo de los iusnaturalistas clásicos hispanos y su empeño por conjugarlo con el pensamiento ilustrado de la tradición krausista, en la común convicción que ambos tenían por revalorizar el papel social y 
democrático de las instituciones políticas tradicionales hispanas. Ello se pone particularmente de manifiesto en su afán por hallar afinidades entre el pensamiento del filósofo y teólogo jesuita Francisco Suárez con el pensamiento de su maestro, Francisco Giner, quienes, en efecto, presentaban profundas afinidades en materia de sociología y de filosofía política:

Se trata, no más, de notar cierta relación analógica entre el punto de vista del teólogo y filósofo de los siglos XVI y XVII (1548 a 1617) y su manera amplia de ver y definir, de concebir la «sociedad humana» en el «sistema» del mundo, de la realidad y de la vida: obra divina como un orden substantivo, o mejor, como un «Cuerpo», y el punto de vista de la concepción «orgánica» de la realidad, y en ella y como ella, de las «sociedades», sostenido por el maestro y filósofo del siglo XIX (y principios del xx, 1829-1915). [...] Hállanse ambos filósofos [Suárez y Giner] - magni hispani-, cada cual a su modo y en su momento, dentro de una de las corrientes más constantes y constructivas de la historia del pensamiento, como ahora diríamos, «sociológico»y «político» (Posada, 1928: 118-119).

En ese contexto se sitúan, pues, las obras de Francisco Giner, Adolfo Posada y Joaquín Costa, junto con otros de los más representativos exponentes del krausismo español y del espíritu regeneracionista del 98, que mostraron tener una notable erudición sobre el pensamiento jurídico y político hispano del Siglo de Oro y que hicieron sus aportaciones a este sector de la historiografía filosófico-jurídica de la Escuela de Salamanca. Se produce así lo que podríamos considerar un revival del iusnaturalismo en este periodo de la Edad de Plata española, en el que los regeneracionistas vuelven su mirada hacia los escritores del Siglo de Oro para buscar en ellos, como exponentes de los ideales de la España anterior a un largo periodo de decadencia, estímulos y revulsivos para reformar la vida cultural y política en España.

Ese propósito determina que su revisión de los clásicos suponga una lectura «interesada» —en el mejor de los sentidos del término- y que, las más de las veces, se subordine su gusto por la erudición filológica y metafísica a la intención pragmática que pretenden derivar de ese pensamiento hacia los problemas acuciantes del contexto ideológico del regeneracionismo de la España de finales del siglo XIX y principios del XX; por ejemplo, en su reivindicación de las libertades de los ciudadanos y de las personas sociales, de unos principios universales para el Derecho Internacional, la orientación de toda política al bien común, así como el derecho y el deber del pueblo a resistir la tiranía mediante la desobediencia a las 
leyes injustas, etc., ideas todas ellas presentes en el iusnaturalismo de la Escuela de Salamanca que vuelven a adquirir vitalidad y a fortalecerse en la doctrina krausista, y cuyas consecuencias se van a proyectar en todos los aspectos de la vida cultural y política española.

Dados, pues, estos antecedentes, encontramos en el citado artículo de Posada un testimonio de estas relaciones entre las concepciones generales de la Filosofía del Derecho y Sociología de Francisco Giner de los Ríos (1839-1915), con las ideas sobre el corpus mysticum de Suárez (15481617) expresadas en el De Legibus, en las que el krausismo encontraría, de modo indirecto, también su raíz histórica y doctrinal. La recuperación de esta idea del corpus mysticum a la que Posada dedica su estudio, a la manera en que lo expuso Francisco Suárez entre los escolásticos, vino principalmente de la mano de la noción de organicismo social y la caracterización de la sociedad hecha por la filosofía jurídica krausista y, a su través, por la obra de Rousseau: «A su tiempo, Rousseau, en el siglo XVIII, hablará del "yo común" de la sociedad que surge del pacto, y el "cuerpo místico" de Suárez resurgirá en las concepciones modernas del organismo social, como veremos en Giner» (Posada, 1928: 119).

El interés de Posada por hallar analogías entre las doctrinas de los magni hispani de la Escuela de Salamanca y las concepciones sociológicas y jurídicas de la moderna teoría gineriana del organismo social — por oposición a las teorías del individualismo atomista - representa un punto de inflexión muy interesante para la comprensión de la relación que Giner establece entre sociedad y Estado, entre la cuestión social y la cuestión política.

Vista con una lente del siglo XXI, la trascendencia de esta idea de la razón práctica, y la consiguiente distinción entre Estado y sociedad, aparecen como algo decisivo, y toda la doctrina adquiere un matiz de actualidad. Aunque ni Suárez ni Giner se plantearon el problema que ha agitado a la conciencia científica de hoy, es, sin embargo, un hecho que trazaron con toda claridad esta diferencia entre el Estado oficial y el Estado no oficial, y que la misma puede poseer, en sí, un gran alcance para la teoría social contemporánea. Por esta razón consideramos muy valioso el empeño de Posada de buscar «coincidencias de concepto o de orientación, o de puntos de vista, entre los grandes pensadores que han intentado dar solución o explicación a algunos de los eternos y constantes problemas, dignos siempre de la reflexión humana» (1928: 117), y, por tanto, creemos que merece la pena seguir indagando en las conexiones que hay en la doctrina jurídica y social de ambos pensadores. 
Pensamos que este análisis de la naturaleza de la sociedad, tan esencial en Derecho como en Sociología, y del carácter real y sustancial de las personas sociales ginerianas - entendidas a la manera del corpus mysticum suareciano como corporaciones donde hay un consorcio de voluntades-, puede suscitar nuevas respuestas a la luz de los nuevos conocimientos de la sociología y la cultura jurídica presente, así como ofrecer algunas claves para la comprensión del legado doctrinal de los pensadores clásicos. Así lo ha hecho ver Rainer Specht en su artículo «Derecho natural español. Clasicismo y modernidad», donde afirma que la herencia intelectual de los principales tratadistas del Derecho Natural constituye

un punto culminante de la Filosofía práctica formulada en términos de moral science, y se cuenta entre las construcciones más impresionantes que ha forjado nuestra civilización: una Filosofía práctica que abarca toda la realidad. Que haya sido olvidado por nuestra conciencia cultural, a veces poco cuidadosa en la conservación de los fenómenos, es una de las razones que impiden hoy a la opinión pública comprender a Europa como unidad cultural (Specht, 1990: 343-354).

Nos referiremos, pues, a esta valiosa y persistente tradición de pensamiento de los magni hispani, que tiene en Francisco Suárez a uno de sus más excelsos representantes, para tratar de establecer cuáles fueron los rasgos distintivos comunes de esos clásicos iusnaturalistas, ver si se dio entre ellos algún tipo de coincidencia de inquietudes o incluso de comunidad de método o enfoque, y, finalmente, para indagar en qué consistió su legado doctrinal y qué aspectos tuvieron una mayor amplificación a finales del siglo XIX y principios del Xx, tal y como fueron recibidos por el krausismo decimonónico español. Desde luego, dar cuenta pormenorizada de las diferentes actitudes hermenéuticas avanzadas de esos pensadores iusnaturalistas resultaría una tarea excesiva, cuando no inabarcable, por lo que nos limitaremos a bosquejar un itinerario orientador de los principales aspectos y posiciones más representativos de esta Escuela de Derecho Natural a fin de analizar sus posiciones doctrinales en temas que fueron apreciados y desarrollados por los krausistas españoles y que todavía siguen abiertos en los debates contemporáneos, como es el problema de la definición y función de los conceptos de razón práctica y epiqueya. Tratemos, pues, de resumir los aspectos básicos más modernos del pensamiento clásico iusnaturalista español, circunscribiendo nuestro análisis de la Escuela de Derecho Natural a aquellos rasgos comunes de su concepción del Derecho que han sido elaborados, secundados e interpretados por la literatura crítica krausista. 
Una de las tesis principales de la Escuela de Derecho Natural española es la fundamentación racional del orden jurídico, lo cual supone, como punto de partida, un rechazo de las tesis no-cognitivistas - como el escepticismo, relativismo e irracionalismo- en tanto en cuanto el iusnaturalismo defiende la competencia de la razón práctica para fundamentar las normas y juicios morales. La incompatibilidad con estas corrientes nocognitivistas es clara, pues al afirmar los escépticos y relativistas la indeterminación radical del Derecho, renuncian así a una de las notas más esenciales para el iusnaturalismo español, al elemento deliberativo y racional que es capaz de generar expectativas de reforma en la sociedad, dado que sus tesis escépticas impiden todo intento de justificación racional. Buena muestra de ello es el escepticismo con el que muchos autores críticos se refieren a los derechos fundamentales, lo cual evidencia también un cierto alejamiento de lo que hoy constituye una seña de identidad de las tesis progresistas y de las posiciones doctrinales que, tanto en la época de Giner como en nuestros tiempos, sostienen con mayor énfasis la fe en el Derecho y la lucha contra la injusticia que este promueve. Así lo hizo notar uno de los más importantes discípulos de Giner, Adolfo Posada, en la traducción directa del alemán de La lucha por el Derecho de Rudolf von Ihering:

aquí se habla de la lucha del Derecho contra la injusticia. Si en esta hipótesis el Derecho no lucha, es decir, no hace una heroica resistencia contra aquella, se negará a sí mismo. Esta lucha durará tanto como el mundo, porque el Derecho habrá de prevenirse siempre contra los ataques de la injusticia. La lucha no es, pues, un elemento extraño al Derecho; antes bien, es una parte integrante de su naturaleza y una condición de su idea (Ihering, 1974: 7-8).

Se trata, en efecto, de emprender una lucha por el Derecho, por decirlo con una expresión que tanto gustaba emplear a krausistas como Posada o Giner. Esta fórmula no solo es el título de un libro de Ihering que Posada tradujo al español, sino que tuvo una mayor significación, sirviendo casi podríamos decir de lema frente a la pobreza de ideales del positivismo vigente abocado al inmovilismo social, y sirviendo al mismo tiempo de acicate para los ánimos decaídos, pues hay momentos, como dice Giner siguiendo en esto a Ihering, en que «el teórico se anticipa al sentido de su época» (1899: 30).

El prólogo de Clarín a esta obra de Ihering resume muy bien las enseñanzas que había recibido de Giner en sus clases de doctorado, e interesa traerlo a colación porque está impregnado de las aspiraciones o ideales 
krausistas en la lucha contra la injusticia que se libraba en el contexto decimonónico español:

[son] sofismas que se conocen con nombres más o menos huecos, más o menos bárbaros; sofismas que toman su apariencia de argumentos de donde pueden, ora de las ciencias naturales, y hablan entonces de evolución; ora de mal interpretados positivismos y experimentalismos, y entonces hablan de lo posible, de lo oportuno, de lo práctico, de lo histórico. Y existe una íntima relación entre una y otra enfermedad de nuestro espíritu liberal, y por esto, si del mal primero, del formalismo, se puede decir que ya casi todos hace tiempo están contagiados, no será extraño que la nueva laceria, el posibilismo que se llama, o quietismo que podría llamarse, lleguen a padecerla aquellos liberales que hoy no la conocen, por fortuna. Es evidente que un mal se engendra de otro: poco importa que los apóstoles de la pasividad política, del indiferentismo disfrazado de hipócritas apariencias de misticismo político se digan inspirados por la ciencia, por la moderna idea, por los adelantos de los estudios históricos y naturales; de todo esto toman el color, pero en calidad de enfermedad el quietismo (que también podría decirse jobismo, ya que tanto agradan los nombres nuevos) se deriva necesariamente de la influencia formalista que por vicio secular padece el concepto del derecho más vulgarizado (Clarín, 1921: XII-XIII)

Bien se aprecia en estos fragmentos cómo los iusnaturalistas krausistas emprenden sus críticas contra el escepticismo y las tesis inmovilistas a que abocaba el positivismo normativista más formalista, pues al centrarse este en discursos descriptivos o meramente explicativos, cuando no puramente críticos de cualquier intento de legitimación del Derecho, no se dejaba lugar para un discurso justificativo, imposibilitando así algo que es crucial para el krausismo: que se pueda dar cuenta del discurso interno del Derecho, de su relación con la moral, de su legitimación. En verdad, hay en el fondo de las tesis irracionalistas y del emotivismo ético algo contrario a la filosofía jurídica krausista: la consideración de la justicia como un ideal irracional y, en consecuencia, la negación total de la posibilidad misma de la razón práctica. Esta visión posmodernista del Derecho, naturalmente más presente hoy en día que en la época de Giner, y cuya trayectoria se deja sentir también en ese periodo de finales del XIX y principios del Xx en que Giner escribe, puede mostrarse en la obra de algunos autores contemporáneos del realismo jurídico (Frank, Wendell \& Nickerson, 2008: 117-133) y en los enfoques críticos del derecho (Boaventura o Kennedy), quienes comparten también este carácter antirracionalista que les lleva a defender versiones fuertes de escepticismo epistemológico y 
de relativismo cultural y que hacen, por lo tanto, imposible un discurso propiamente justificativo.

Pero si se aceptaran las tesis escépticas y puramente descriptivas de su teoría crítica, ¿para qué preguntarse entonces por la posible mejora del ordenamiento jurídico o por la relación entre Derecho y Moral, que, como sabemos, es uno de los grandes temas de la Filosofía del Derecho krausista? Obviamente, para los escépticos, formular esta pregunta no tiene sentido y no aporta nada a la ciencia jurídica. Y es precisamente aquí donde radica una de las críticas más certeras que hacía Clarín (1921: XIIXIII) a estas tesis escépticas por incurrir en una especie de contradicción pragmática, pues se trata de una concepción que, al mismo tiempo que trata de promover cierto compromiso con la práctica, renuncia a establecer criterios que puedan servir de guía a esa práctica, abocándonos así a esa enfermedad del quietismo estéril. Por lo tanto, el escepticismo no solo viene a refutarse a sí mismo por ser un principio impráctico, sino que lo hace de manera peligrosa al minar por su base cualquier intento de discurso racional y, en tal sentido, nos parece que la doctrina krausista aporta una perspectiva más ajustada y cabal del Derecho.

Ciertamente no todas las críticas dirigidas al escepticismo por los defensores de una racionalidad práctica han sido tan certeras; positivistas como Norberto Bobbio o Hans Kelsen también han criticado ese supuesto idealismo y falta de realidad que habría en el iusnaturalismo, no para minar de modo tajante cualquier posibilidad de fundamentación del Derecho, sino para salvar precisamente el pluralismo de los sistemas de legitimidad y defender que las normas de justicia no constituyen sino valores relativos:

La negativa a admitir, desde el punto de vista del conocimiento científico, la existencia de un ser trascendente situado por encima de toda posible experiencia humana, es decir, la oposición a la existencia de lo absoluto en general y de valores absolutos en particular, conduce, desde el punto de vista de una teoría científica del derecho, a la afirmación de que la validez del derecho positivo no puede depender de su relación con la justicia. Semejante dependencia no podría, en efecto, existir más que si la justicia fuese un valor absoluto, es decir, si se supone la validez de una norma de justicia que excluye la validez de cualquier otra norma que no esté conforme con aquella. Si se admite que puede existir una pluralidad de normas de justicia diferentes y eventualmente contradictorias, en el sentido de que cabe presuponer como válida tanto una como otra de dichas normas, y si, por consiguiente, el valor de justicia se presenta como relativo, resultará que todo ordenamiento jurídico positivo entrará fatalmente en contradicción con una u otra de estas normas de 
justicia y no habrá, por tanto, en virtud de esa contradicción con alguna de las normas de justicia, ordenamiento jurídico positivo que no deba ser considerado inválido. Pero, al mismo tiempo, y por otra parte, todo ordenamiento jurídico positivo puede ser conforme a una cualquiera de las numerosas normas de justicia que solamente constituyen valores relativos sin que esta conformidad sea considerada como fundamento de su validez (Kelsen, 1966: 100-101).

Los autores positivistas contemporáneos consideran que una norma puede ser válida sin necesidad de que sea justa, pues parten de la total independencia del Derecho en su relación con la justicia. En tal sentido, denuncian el idealismo caballeresco y escapista del iusnaturalismo, al cual, un realista como Holmes, refiriéndose a este mismo empeño iusnaturalista de preservar una idea de justicia universal, lo había comparado en una ocasión con los caballeros a los que no basta con que se reconozca que su dama es hermosa, sino tiene que ser la más bella que haya existido y pueda llegar a existir (Holmes, 1920: 310; citado en Atienza, 2005: 25-34). Este argumento, en tono un tanto sarcástico, vendría a recusar esa vocación de universalización e inmutabilidad que hay siempre en las tesis iusnaturalistas.

A este respecto, y ante una eventual crítica positivista a la filosofía krausista, conviene advertir que no hay en el krausismo una complacencia ni un asentimiento acrítico que imponga una ley natural de modo abstracto y uniforme. Como puede deducirse de las obras de Giner y Posada, los krausistas españoles son conscientes de que todas las creencias y valores son relativos a otras creencias y valores, así como a la comunidad y las prácticas sociales determinadas en que se aplican. Ahora bien, la aceptación de esta tesis no nos conduce necesariamente a la tesis relativista que sostiene que la crítica es imposible entre distintas culturas:

No todas las prácticas sociales están, entonces, blindadas contra todo tipo de crítica por razones. Nadie afirma que sea imposible criticar todo tipo de creencias (y esto implica creer que al menos algunas prácticas pueden ser criticadas). Afirmar tal cosa significaría negar que los individuos pueden cambiar de creencias en virtud de las razones de otros y de las propias (Valdecantos, 1999: 57).

Conviene, pues, distinguir bien esta versión del escepticismo contemporáneo - contra la que se pronuncian los krausistas y los iusnaturalistas clásicos-, cuya obsesión es probar que todas las creencias son incapaces de resistir a la crítica, por oposición a lo que constituía el fin del escepticismo clásico, a saber: buscar el modo en que cualquier creencia puede ser puesta en cuestión, lo cual implica un clima mental de respeto y aprecio 
por lo diferente, que está en la línea de esta tradición clásica española, en la que hay una clara apuesta por el diálogo y la racionalidad de la acción. No otra cosa propone el krausismo español que, por encima de sus posicionamientos, supone la elaboración y reelaboración de una doctrina de manera libre, autónoma y sin prejuicios, para la cual, dice Giner, «todo acto de justicia contribuye a afirmar esta virtud en la conducta, no solo por lo que el hábito consolida la recta disposición del sujeto, sino por el influjo de su ejemplo sobre los demás: aquí es donde se halla la mejor garantía» (1926: 136).

Este principio racional del orden jurídico es el que sería posteriormente reelaborado por el iusnaturalismo krausista del siglo XIX y de principios del siglo Xx, particularmente en su concepción de la racionalidad como libertad, que exige que la norma moral que la acción cumple satisfaga el principio de universalización, es decir, que pueda encontrar un reconocimiento general en su ámbito de aplicación. Por esta razón, la doctrina de los iusnaturalistas clásicos hispanos sigue siendo familiar a la teoría jurídica y política del presente, que es una teoría de la acción racional.

No obstante, conceptos tales como «razón» y «res publica», o el más ambiguo y polisémico de todos de «naturaleza», aunque sean utilizados sin hacer mayores especificaciones, han variado notablemente y adoptado diferentes ropajes en los últimos cuatrocientos años. En general, puede afirmarse que la Filosofía del Derecho de hoy en día pone un mayor énfasis en que la razón debe servirse de orientaciones históricas y sociales; de ahí que Giner haga hincapié en que lo que es recto no lo puede fijar una razón abstracta, sino una razón práctica que se mueve en contextos históricos determinados y que se dirige a fines concretos:

[Se trata de la] dilucidación en cada momento de lo que hay de eterno y permanente (principio de la filosofía), lo que hay de temporal y mudable (hechos de la historia) y la acomodación de los principios a los hechos (filosofía de la historia). [...] Manifiéstase el Derecho en una serie de estados particulares, necesariamente mudables y sucesivos, que son sus manifestaciones temporales, o los hechos jurídicos. La serie toda de dichos estados en que el Derecho, sin perder por eso nada de su inagotable fondo, se muestra, es lo que constituye la vida del Derecho: pues que en general es la vida aquella propiedad por la que un ser determina su esencia y cualidades en estados sucesivos (Giner, 1916: 58).

Esta concepción de la racionalidad práctica que retoman los krausistas tiene, pues, un claro precursor en el papel que los iusnaturalistas clásicos españoles concedieron a la fuerza de la razón en el Derecho. En virtud 
de este principio racional, los iusnaturalistas clásicos han sido considerados como el eslabón entre el Derecho Natural clásico y el moderno. Sin embargo, su concepto del Derecho, como toda doctrina de transición, presenta rasgos ambivalentes, pues siguen fieles a una fundamentación metafísica del orden jurídico y a unas «razones últimas» de tipo ontológico que conforman el substrato axiológico material de sus construcciones. Por esta razón, de los clásicos españoles, en su papel de eslabones de conexión entre el pensamiento medieval y el moderno, se ha dicho que les incumbe una tarea decisiva en el proceso de secularización del iusnaturalismo teológico medieval que condujo a la Escuela del Derecho Natural racionalista. A este respecto conviene recordar, por ejemplo, cómo Francisco Suárez coadyuvó a la formación del imperio de la ley al proclamar que, tras las disposiciones específicas de la ley, existían unas normas racionales de validez general, que él llamó ley natural, a la que todos estamos sometidos y que a nadie, ni siquiera al papa, le estaba dado modificar. De igual modo, los argumentos de la Escuela de Derecho Natural española llevaron hasta sus últimas consecuencias el postulado tomista de la autonomía del orden humano regido por la racionalidad natural, respecto al orden trascendente de la fe y de la gracia, lo cual implicaba un abandono del objetivismo ontológico en función de un subjetivismo tendente a potenciar la dimensión del Derecho como conjunto de facultades de la persona; una doctrina que preanunciaba la modernidad y que conocería un desarrollo mayor en el concepto de Derecho inmanente gineriano: «En la fidelidad [de Giner] al principio de la inmanencia en el Derecho, se encuentra, a nuestro juicio, la base de la que con razón llama el señor Dorado Montero (El Derecho y sus sacerdotes, pág. 580, nota) escuela española de filosofía del Derecho» (Ríos Urruti, 1916: 110-111).

Se opera, pues, una transición del a priori trascendente que imponía una realidad objetiva con la indiferencia soberana de la omnipotencia divina, a un a priori práctico de la voluntad, inmanente, basado en la necesidad natural del hombre considerado en su estado originario.

En cualquier caso, y habida cuenta de sus limitaciones, es en estas concepciones racionalistas donde reside la gran aportación del Derecho Natural a la conformación del humanismo, al desarrollo de las libertades y a la legitimación democrática del poder. Por esta razón, consideramos que en la actual coyuntura filosófico-jurídica, abierta al reconocimiento de la competencia práctica de la razón para establecer pautas éticas 
fundamentadoras de una convivencia social justa, la doctrina de los clásicos iusnaturalistas hispanos sigue representando un provechoso estímulo.

Otro aspecto recurrente en las aportaciones bibliográficas actuales al estudio de los iusnaturalistas clásicos hispanos es el referido a su papel en la génesis y evolución de los derechos humanos y en el reconocimiento de su decisiva participación en la génesis del Derecho Internacional. En esta materia, destacan sobre todo las tesis humanitarias de Bartolomé de las Casas en el Debate de Valladolid (1550) y del considerado hoy padre del Derecho Internacional, Francisco de Vitoria, en respuesta a los problemas éticos planteados por el descubrimiento de América. Vemos, pues, que a estos autores clásicos hispanos les incumbió un decisivo papel en la constitución del acervo teórico iusnaturalista que conformaría luego el Derecho Internacional. Una vez más, su punto de vista sobre la ley natural se vio puesto a prueba y, nuevamente, su concepto de Derecho no quedó reducido a un código rígido e inmutable, sino que supieron adaptar a los nuevos tiempos y a las exigencias concretas de su época los preceptos del Derecho Natural, dando solución a numerosos conflictos éticos y jurídicos que les fueron planteados por vez primera.

Asimismo, debe recordarse que en este contexto histórico e ideológico de los siglos XVI-XVII se estaban fraguando las bases de la Teoría del Derecho Natural moderno, las cuales estaban ligadas a una serie de rasgos característicos de su marco político, como fueron la aparición del Estado moderno, las teorías absolutistas y la consolidación de la potente locomotora de la «razón de Estado» que arrasaría en Europa en el contexto de las doctrinas monárquicas (Sabine, 1965: 291 ss.).

Detengámonos un poco en este aspecto, pues iusnaturalistas clásicos como Francisco Suárez defendieron un concepto de soberanía opuesto al de estas doctrinas de las monarquías absolutas de su tiempo y a la puesta en marcha del concepto de razón de Estado de Maquiavelo. Un enfoque suareciano del Derecho que, al mismo tiempo que se enfrenta a estas doctrinas de la «razón de Estado», guarda una estrecha relación con la definición de soberanía que ofrece Francisco Giner nada desdeñable.

Como es bien sabido, la reflexión de Maquiavelo sobre la razón de Estado parte de desprender o separar la filosofía política de toda teología y ética, para así ganar la autonomía de lo estrictamente político. Se trata de una secularización de la soberanía consistente en hacer valer la independencia total del Estado. De acuerdo con Maquiavelo, el Estado puede y debe ser amoral, inmoral o moral según convenga, es decir, según la razón misma de su conservación y del incremento de fuerza, pues de lo 
que se trata es del «Estado», de su razón, de incrementar su poder. De aquí proviene el manido lema de que el fin justifica los medios, según el cual, el fin de incrementar su poder justificaría todos los medios empleados, desde mentir hasta no respetar los convenios ni las promesas, así como el uso retórico del Derecho por el Príncipe para mantener ciertas apariencias engañosas en su provecho. Por lo tanto, no se toma en consideración la moralidad de los medios empleados, ni se trata de descubrir eso «justo» que hay en el Derecho; por este motivo, en lugar de la dialéctica como método de razonamiento encaminado a la verdad, cuyo conocimiento es posible y necesario para los iusnaturalistas, se ensalza el valor de la retórica en ese nivel básico instrumental para servir mejor a la razón de Estado.

Todo esto se traduce en materia de política internacional, podríamos decir con Hobbes, en el reino del estado natural en que cada Estado queda abandonado a sus propias fuerzas, pues de lo que se trata es que cada uno busque su propia auto-afirmación, su propio provecho. «Mi patria ante todo, con razón o sin ella», o, en otras palabras, «legalidad, con moralidad o sin ella», una expresión reivindicada por algunos juristas positivistas contemporáneos en la que reverberan ciertos ecos de la tesis de Maquiavelo, donde lo que pasa a primer plano no es cuestionarse por la justicia de determinada resolución, sino preguntarse qué bien particular nos ha de traer proseguir con determinada política para mantener el Estado, es decir, todo aquello que hace que persista en su ser, que aumente su fuerza, sin importar los medios que puedan emplearse para alcanzar dichos fines. En estas sentencias queda claramente expresada la razón de Estado, la consideración de los fines utilitarios que puedan ayudar al Estado, sin consideración alguna de una conciencia universal de justicia. Por esta razón, krausistas como Fernando de los Ríos no dudan en dirigir sus más encendidas críticas a las doctrinas que persiguen un estatalismo exacerbado:

El Estado, pues, no nace, para estos pensadores, porque haya de cumplir una misión esencial y positiva a lo humano, sino porque es preciso un orden inhibitorio que paralice las acciones dañosas que intentemos realizar, o las castigue una vez cumplidas. ¿Es otra la razón que determina en Kant el advenimiento del Derecho público? Se trata para él, simplemente, de asegurar lo mío y lo tuyo, que ya tenemos en el estado de naturaleza; de aquí que el Derecho público o civil, como le llama él con exactitud, a nuestro juicio, no tenga un contenido jurídico propio; su razón de ser es amparar, vigilar para que no se haga; es, pues, el Estado policía, como gráficamente ha sido designado, y al Derecho, que de él se ocupa, se le llama adjetivo. Su necesidad no se funda en lo que hace, sino en lo que evita hacer; no por la moralidad que tengamos, sino por aquella de que 
carecemos, surge el Estado; es un recuerdo perenne de nuestra imperfección (Ríos Urruti, 1916: 184-185).

De modo semejante a como los krausistas se opusieron a las tendencias formalistas y estatalistas del Derecho, la obra de Suárez y de los tratadistas iusnaturalistas de la Escuela de Salamanca en general, apunta también en una dirección completamente opuesta a esta de Maquiavelo y de Hobbes, trazando en este sentido lo que podría denominarse como una línea antimaquiavélica en la filosofía jurídica española que llega hasta los krausistas:

error de Maquiavelo y de los políticos: que ante el gobierno temporal no hay que preocuparse de lo espiritual. Acerca del problema propuesto pueden citarse dos opiniones. Una es que poder seglar y el derecho lo que buscan directa y primariamente es la estabilidad política y su conservación; que el tema y, por consiguiente, la materia de las leyes es lo que sirve para la estabilidad política y para su conservación y progreso; y que en orden a este fin se dan las leyes, ya se encuentre en ellas una verdadera honestidad, ya solamente una honestidad fingida y aparente, incluso disimulando lo que es injusto si resulta útil para el estado temporal. Es la doctrina que los políticos actuales, y el que más ha tratado de persuadirla a los príncipes seglares ha sido Maquiavelo, fundándose únicamente en que de otra manera no puede conservarse el estado temporal, de donde procede su perverso juicio de que no puede ser rey verdadero y inestable quien se atiene a las leyes de la virtud y se somete en todo a ellas (Suárez, 1967: 240-246).

A esta línea de pensamiento antimaquiavélica en España coadyuvó la noción del «bien común», otro de los conceptos clave de la Escuela de Salamanca, gracias al cual se logró imprimir una orientación y carácter a la doctrina iusnaturalista que ha sido muy fecunda para posteriores versiones iusnaturalistas como la krausista. De acuerdo con este concepto central del bien común, se determinaba que el fin del buen Príncipe no es otro que el bien de la comunidad. Por ello, en aras de conseguir y preservar el citado bien común, ciertos principios de justicia debían condicionar el ejercicio del poder político, lo que venía a justificar y legitimar el reconocimiento del ius belli (más usualmente conocido por la expresión escolástica de la guerra justa, bellum justum). Aquí quedaba fundado el derecho de resistencia frente a un gobierno tiránico, esto es, el derecho a la resistencia activa cuando el rey obre contra las normas del Derecho Natural o abandone el fomento del bien público. Sobre esta cuestión, sentencia Francisco Suárez que cuando el monarca traspasa el límite de la esfera de sus atribuciones lícitas, entonces debe renacer la soberanía popular originaria. 
Asimismo, de la idea del bien común se deriva también otro principio determinante muy ligado a lo anterior: la idea de que la justicia está por encima de las conveniencias políticas, de las razones patrióticas o de Estado, puesto que es algo que va más allá de cualquier pueblo. Se trata, pues, de sentar unos principios de justicia que interesen a toda la humanidad, pues no son los intereses particulares de uno u otro Estado lo que está en juego, sino la idea misma de justicia. De acuerdo con la doctrina iusnaturalista, la idea del bien común debe prevalecer sobre los intereses particulares del Príncipe y sobre esa razón del Estado maquiavélica a la que nos hemos referido; gracias a este principio moral entre los pueblos, fue posible hablar de la necesidad de «causa justa» para la declaración de la guerra y para sentar las bases del Derecho Internacional que tan importante fue luego para asentar el Ideal de la Humanidad krausista: «el género humano, aunque de hecho está dividido en pueblos y reinos, mantiene, sin embargo, en todo momento una cierta unidad, no ya solo la específica, sino cuasipolítica y moral como lo indica el precepto natural de la solidaridad y ayuda que se extiende a todos, incluso extranjeros y de cualquier nación» (Suárez, 1967: 135).

De lo dicho puede colegirse cómo la noción del bien común (Gemeinwohl) consiguió, por un lado, establecer los límites del poder estatal, fundamentar los derechos humanos, y por otro lado, sentar las bases de un modelo de referencia para el Derecho Internacional humanitario, que sirviera para controlar el empleo de ese instrumento terrible, y al mismo tiempo necesario, que es el Derecho.

Pero, indiscutiblemente, uno de los aspectos más estudiados en la Escuela de Salamanca, y que más tarde pasaría a ocupar un lugar central de la filosofía jurídica y política gineriana, es el que contribuyó a consagrar las libertades fundamentales del individuo, aunque con el caveat -que conviene considerar y que se pone de manifiesto en el completo e interesantísimo libro del profesor Antonio-Enrique Pérez Luño sobre este periodo histórico, cuya exposición aquí seguimos de cerca- de que «fueron ideas elaboradas para un contexto presidido por una ética social sin asomo de derecho individual; siendo el nuestro tiempo de derecho individual sin ética social» (1992: 116).

Así - tal como se ha puesto de manifiesto en algunos manuales de Derecho Constitucional-, conviene «advertir, con Álvarez Conde, que "en la defensa de los derechos del hombre es donde mejor encontramos la modernidad de esta Escuela, y su aportación a la democracia junto con el principio de soberanía popular matizado, que encontramos en Suárez". 
En definitiva, es en la Escolástica española donde comienza a andar el camino que con el tiempo culminará en el Estado Constitucional» (Navas \& Navas, 2005: 54).

Al manifestar de modo terminante e inequívoco que la salvación moral del sujeto humano era algo regulado por la ley moral natural y, por tanto, que era una cuestión que debía ser decidida por el individuo — sin que en esta materia el derecho positivo debiera imponerle una regulación imperativa-, se estaba asentando la base fundamental de los derechos de libertad, de la cual luego se impregnaría el krausismo, y muy especialmente, «la concepción sociológica ética y jurídica de Giner, alcanza[da en] el principio de lo "inmanente" en el Derecho» (Posada, 1928: 119-120), al que Giner dota incluso de entidad jurídica como Estado individual.

A este respecto, tal teoría iusnaturalista plantea un problema ético fundamental, que no solo atañe a los juristas, sino a cualquier persona preocupada por los límites del Estado y de sus servidores, y que establece que solo se debe obedecer a la autoridad en cuanto se mantenga dentro de sus atribuciones legales y no ataque u olvide los imperativos del Derecho Natural, lo cual implica la remisión a criterios morales para legitimar el orden jurídico. En este plano de la fundamentación de los derechos humanos, frente a las posturas individualistas y positivistas, tanto los clásicos hispanos como los krausistas españoles decimonónicos defienden y reivindican el fuero de una posición intermedia (social-individualistische). Dicha posición sería la única capaz de conjugar los valores individuales de la persona en función de su racionalidad, con la sociabilidad natural humana heredada de la tradición aristotélico-tomista que define al hombre como zoon politikon y que, por tanto, concibe la plena realización del ser humano en su incorporación a la sociedad y al Estado. De hecho, entre los aspectos que caracterizaron el pensamiento político krausista destaca precisamente su confianza en la sociedad como un elemento nuclear e intermedio entre el individuo y el Estado, y cuya autonomía encuentra en el concepto de selfgovernment su mejor expresión ${ }^{2}$.

Confiamos en que este breve esbozo de las principales tesis de la Escuela de Salamanca sobre el Derecho, la política y las libertades, sirva

2. Sobre la complexión y alcance del Estado social y el Estado individual en la obra de Francisco Giner, véanse los artículos «Dos en uno. El concepto de Estado individual krausista y su relevancia biopolítica» (2009) y «La micrópolis del yo. Representación, soberanía e individuo en los escritos de Francisco Giner de los Ríos» (2007: 199234) de José Manuel Vázquez-Romero. Sobre el autor que popularizó el concepto del selfgovernment, Gumersindo de Azcarate, véase Capellán (2005). 
para asentar algunos de los principios fundamentales de la Filosofía del Derecho gineriano y ayude a comprender su posición doctrinal y sus esfuerzos por vincular el Derecho a la Moral como un medio objetivo y necesario para garantizar su realización.

A modo de síntesis, puede concluirse que la vindicación de la superlativa necesidad de armar al individuo de una malla férrea de garantías por medio del concepto de racionalidad práctica que garantice la limitación democrática del ejercicio del poder estatal y el arbitrio del poder público, y que ya estaba presente en estado embrionario en los autores de la Escuela de Derecho Natural española, es un pensamiento que ha tenido gran proyección e influencia en el iusnaturalismo hispano: primero en la Ilustración, lo cual puede verse en el gran protagonismo cultural que tuvieron los miembros de la Escuela de Derecho Natural y su implicación en episodios clave de la formación de la identidad moderna — ello ha sido analizado por diversas obras que estudian este nexo entre la Compañía de Jesús y la modernidad (Betrán, 2010)—; y posteriormente, a través del tamiz de la filosofía krausista, donde conoce un nuevo desarrollo, con una proyección en el pensamiento contemporáneo que alcanza hasta nuestros días, donde conserva su interés en el proceso de fundamentación de los valores de los Estados de Derecho y donde encuentra su mejor realización práctica en todos los regímenes constitucionales de los países efectivamente civilizados ${ }^{3}$.

\section{Bibliografía citada}

ATIENZA, M., «Argumentación jurídica y Estado constitucional», en María José Añón \& Pablo Miravet Bergón (eds.), Derecho, justicia y Estado, Valencia, Tirant lo Blanch, 2005, pp. 25-34.

BETRÁn, J. L., La Compañía de Jesús y su proyección mediática en el mundo hispánico durante la Edad Moderna, Madrid, Sílex Ediciones, 2010.

CAPellán de Miguel, G., Gumersindo de Azcarate: biografía intelectual, Valladolid, Junta de Castilla y León, 2005.

[CLARÍN] GarCíA-AlaS Y UReÑA, «Prólogo» a Rudolf Von Ihering, La lucha por el Derecho, trad. Adolfo Posada, Madrid, Nueva Edición, 1921.

Frank, J., O. Wendell Holmes \& K. NiCKerSOn LleWellyn, «Legal Realism and Skepticism», en J. Feinberg \& J. Coleman (eds.), Philosophy of Law, Belmont (USA), Thomson Higher Education, 2008, 8. ${ }^{a}$ ed., pp. 117-133.

3. Véase al respecto uno de los más recientes estudios colectivos dedicados al pensamiento gineriano (Vázquez-Romero, 2009a) donde se pone de manifiesto la actualidad de la obra de Francisco Giner. 
GINER DE LOS Ríos, F., «La Ciencia, como función social», BILE [Boletín de la Institución Libre de Enseñanza], 23, 1 (1899), pp. 26-32, 55-64.

- \& Alfredo CALDERón, Prolegómenos del Derecho [Obras completas, I], Madrid, Espasa-Calpe, 1916.

- \& Alfredo Calderón, Resumen de Filosofía del Derecho [Obras completas, XIV], Madrid, Espasa-Calpe, 1926.

IHERING, R. von, La lucha por el Derecho, trad. Adolfo González Posada, Buenos Aires, Editorial Heliasta, 1974.

KELSEN, H., «Justicia y Derecho natural», en AA. VV., Crítica del Derecho Natural, ed. y trad. Elías Díaz, Madrid, Taurus, 1966, pp. 29-163.

Navas Castillo, A. \& F. Navas Castillo, Derecho Constitucional: Estado Constitucional, Madrid, Librería-Editorial Dykinson, 2005.

PÉREZ LuÑo, A. E., La polémica sobre el nuevo mundo: los clásicos españoles de la Filosofía del Derecho, Madrid, Trotta, 1992.

PosadA, A., «El "Cuerpo místico" del P. Suárez y el "Organismo social" del Maestro Giner», BILE, 52, 1 (1928), pp. 117-121.

Ríos URruti, F. de los, La Filosofía del Derecho en Don Francisco Giner y su relación con el pensamiento contemporáneo, Madrid, Biblioteca Corona, 1916.

Sabine, G., Historia de la Teoría Política, trad. Vicente Herrero, México, FCE, $1965,3 .^{\mathrm{a}} \mathrm{ed}$.

SPECHT, R., «Derecho natural español. Clasicismo y modernidad», Anuario de Filosofía del Derecho, 7 (1990), pp. 336-390.

SuÁrez, F., Tractatus de Legibus ac Deo Legislatore. Tratado de las leyes y de Dios Legislador [reproducción anastática de la edición príncipe, Coimbra, 1612], edicion bilingüe, trad. J. R. Eguillor Muniozguren, intr. L. Vela Sánchez, Madrid, Instituto de Estudios Políticos, 1967.

ValdeCantos, A., Contra el relativismo, Madrid, Visor, 1999.

VÁzQUEZ-ROMERo, J. M., «La micrópolis del yo. Representación, soberanía e individuo en los escritos de Francisco Giner de los Ríos», Pensamiento. Revista de Investigación e Información Filosófica, 63, 236 (2007), pp. 199-234.

- (ed.), Francisco Giner de los Ríos: actualidad de un pensador krausista, Madrid, Marcial Pons, 2009a.

- «Dos en uno. El concepto de Estado individual krausista y su relevancia biopolítica», en J. M. Vázquez-Romero (ed.), Francisco Giner de los Ríos; actualidad de un pensador krausista, cit. supra (2009b), pp. 27-82.

Fecha de recepción: 13-6-2015

Fecha de aceptación: 8-10-2015 